* Doutor em Ciência Política pela UFPE. Mestre em Direito pela Universidade Federal de Pernambuco. Especialista em Economia pela UFPE. Graduado em Direito pela Universidade Federal de Pernambuco. Professor da Faculdade Damas de Instrução Cristã na graduação e no mestrado do curso de Direito. Auditor-Fiscal da receita Federal do Brasil. E-mail: afccbgp@hotmail.com

** Doutora em Direito pela Universidade Federal de Pernambuco. Mestre em Direito pela Universidade Federal de Pernambuco e especialista em Economia pela Universidade Federal de Pernambuco. Graduada em Direito pela Universidade Federal de Pernambuco. Auditora fiscal da Receita Federal do Ministério da Fazenda aposentada. Professora da Faculdade Damas da Instrução Cristã em Recife. Professora do Adjunta da Universidade Federal de Pernambuco.E-mail:brunaestimaborba@gmail.com

\section{Imposto de Renda da Pessoa Física e Pessoalidade: UMa RELAÇÃo PRECÁRIA E EM DETERIORAÇÃO}

INDIVIDUAL INCOME TAX IN BRAZIL AND THE PERSONALITY PRINCIPLE: PRECARIOUSNESS AND DETERIORATION

\section{André Felipe Canuto Coelho* Bruna Estima Borba***}

Como citar: COELHO, André Felipe Canuto; BORBA, Bruna Estima. Imposto de renda da pessoa física e pessoalidade: uma relação precária e em deterioração. Revista do Direito Público. Londrina, v. 13, n. 1, p. 188-225, abr. 2018. DOI: $10.5433 / 1980-511 \mathrm{X} 2018 \mathrm{v} 13 \mathrm{n} 1 \mathrm{p} 188$. ISSN: $1980-511 \mathrm{X}$.

Resumo: O presente artigo compõe uma série de estudos que investiga o grau de concretização do princípio da capacidade econômica no que se refere ao imposto de renda das pessoas físicas (IRPF). Neste artigo, em especial, é pesquisada a natureza pessoal deste imposto. Utilizando o método indutivo e por meio da revisão doutrinária, normativa e jurisprudencial, as características deste imposto são analisadas. Mediante o exame de dados disponibilizados pela Secretária da Receita Federal, abrangendo o período de 2001 a 2014 e relativos aos grandes números dos rendimentos e deduções declarados, pretende-se demonstrar a precariedade da pessoalidade do IRPF e sua 
deterioração ao longo do período analisado.

Palavras-chaves: Princípios. Capacidade Econômica. Imposto de Renda da Pessoa Física. Pessoalidade.

Abstract: This body of work is part of a series of studies that investigates the degree of physical materialization of the principle of economic capacity with respect to personal income tax (IRPF). With that end, the personal nature of this tax is investigated thoroughly in this research paper. The characteristics of this tax is analyzed through the inductive method applying a doctrinal, normative and jurisprudential review. By examining data made available by the Brazilian Internal Revenue Service from 2001 to 2014 on declared income and deductions, this study aims to demonstrate the precariousness of the personality principle of income tax (IRPF) and its deterioration over the analyzed period.

Keywords: Principles. Economic Capacity. Individual Income Tax. Personality. 


\section{INTRODUÇÃO}

Pode-se afirmar ser pacífico o entendimento quanto à pessoalidade do imposto de renda. Sendo assim, este artigo pretende responder às seguintes perguntas: quanto há, concretamente, de pessoalidade no imposto de renda das pessoas físicas, considerando-se que os princípios da capacidade econômica e da capacidade contributiva estão intrinsecamente relacionados com o atributo da pessoalidade deste imposto? E como tem se comportado a personificação deste imposto ao longo do tempo?

Adotando-se a metodologia de pesquisa qualitativa - revisão normativa, doutrinária e jurisprudencial - e o método indutivo, pretendese demonstrar a precariedade do grau de pessoalidade de que deve ser revestido o imposto de renda das pessoas físicas e sua deterioração no período sob análise, abrangendo os anos de 2001 a 2014.

Para tanto, buscar-se-á compreender o significado da pessoalidade da obrigação tributária, para em seguida caracterizar o imposto de renda como tributo direto e pessoal orientado pelos princípios da capacidade econômica e da capacidade contributiva. Em seguida, investigar-se-á o nível de concretização da pessoalidade na exigência do IRPF e seu comportamento no período em exame. Desse modo, este artigo procurará demonstrar a precariedade da pessoalidade na configuração do imposto de renda das pessoas físicas e sua deterioração ao longo dos anos considerados.

\section{COMPREENDENDO A NATUREZA PESSOAL DO IMPOSTO DE RENDA DAS PESSOAS FÍSICAS}


Entre as muitas formas de o Estado exercer seu poder soberano na obtenção de receitas públicas derivadas, e em especial na imposição de tributos, pode-se mencionar o já obsoleto método de repartição, que assegura "a certeza quanto à soma prevista para cada imposto, enquanto deixava na incerteza a quantia a ser reclamada individualmente dos contribuintes" (BALEEIRO, 2006, p. 211). Contudo, é pelo método da quotidade, em que os valores da arrecadação não são fixados, mas sim os parâmetros para exigência dos tributos, que o Estado exerce atualmente seu poder tributário. A adoção quase universal da quotidade deu ensejo à classificação doutrinária dos tributos de acordo com três grandes teorias ${ }^{1}$ : (i) teoria da capitação; (ii) teoria do sacrifício; e (iii) teoria do benefício.

Pela capitação, os cidadãos pagam indistintamente, per capita, o mesmo montante de tributos, independentemente de quaisquer serviços obtidos do Estado e de quaisquer operações e dispêndios por eles praticados, ou do montante de seu patrimônio e renda. A teoria do benefício, ao contrário, torna o tributo uma obrigação causal, equivalente, contraprestacional ou sinalagmática (TIPKE, 2002, p. 33), tais como as taxas e das contribuições de melhoria, exigidas do cidadão na medida do ônus por ele causado ao Estado. É evidente que a adoção exclusiva da teoria do benefício tende a uma injusta distribuição da carga tributária, visto que são as pessoas menos favorecidas as que, em geral, mais necessitam de prestações estatais individualmente identificáveis, a exemplo de serviços de saúde e educação.

Por essa razão, em sociedades dotadas de uma organização voltada para o atendimento social da população, a exemplo do Brasil, finda-se por optar predominantemente pela chamada teoria do sacrifício,

1 SOUSA (1972, p. 303); SOUSA (s/d, pp. 127-135);XAVIER (1981, p. 42); MARTINS (1979, p.175); BALEEIRO (2006, p. 271); JARACH (s/d, p. 187); NABAIS (1998, p. 199); BERLIRI (1962, pp. 52-53); SCHOUERI (2005, p. 117). 
ainda que por razões pragmáticas se adote a pluralidade ${ }^{2}$ (BALEEIRO, 2006, p. 233) de métodos e teorias de tributação. Baseado no princípio da solidariedade que, no Brasil, consta do art. $3^{\circ}$ da Constituição Federal de 1988 (CF/1988), a todos é imputado o dever de contribuir para o financiamento do Estado de acordo com sua capacidade econômica, independemente das prestações estatais recebidas (SAMUELSON,1979, pp. 176-177). São exigidos, assim, tributos não contraprestacionais, não causais, ou unilaterais, como impostos e contribuições especiais. Cabe lembrar que a Lei n $\mathrm{n}^{\mathrm{o}}$ 5.172/1966, Código Tributário Nacional (CTN), explicitou e deu positividade a essa característica dos impostos, em seu art. 16 afirmando que "Imposto é o tributo cuja obrigação tem por fato gerador uma situação independente de qualquer atividade estatal específica, relativa ao contribuinte." A própria definição de imposto formulada para este tributo impõe a característica de não contraprestação: “prestação pecuniária, exigida aos particulares por via de autoridade, a título definitivo e sem contrapartida, com vista à cobertura dos encargos públicos"(PEREIRA, 2009, p. 13). Rubens Gomes de Sousa - idealizador do CTN - havia definido o imposto como um tributo "que se destina a cobrir as necessidades públicas gerais, isto é, todas aquelas que interessam o grau de interesse que cada um tenha individualmente na existência do serviço ou atividade pública de que se trate" (s/d, p. 130).

Por fim, atendo-se aos impostos, deve-se considerar que eles podem incidir de forma direta ou indireta sobre a capacidade econômica do contribuinte. A classificação de impostos em diretos e indiretos data de 1757 e é atribuída ao marquês de Mirabeau e, já no século XVIII servia para destinguir os impostos diretos como aqueles em que não há

2 Há doutrinadores que defendem a adoção de um imposto único, indireto, como explica Joel Slemrod: "replace the personal and corporate income taxes entirely with some forma of tax consumption - that is, on the portion of income that people spend rather than save". (SLEMROD; BAKIJA, 2004, p. 7). 
repercussão (SOUSA, s/d, p. 135): “celui dans lequel l'impôt n'est pas répercuté" (SELIGMAN, 1913, p. 638). Os impostos diretos, por sua vez, podem ser exigidos conforme as rendas - como o imposto de renda (IR) - ou conforme os bens do contribuinte - a exemplo do imposto sobre a propriedade territorial rural (ITR), e do imposto sobre a transmissão causa mortis e doações de quaisquer bens e direitos (ICD). Quando incide de forma indireta (SOUSA, s/d, p. 135) - como o imposto sobre produtos industrializados (IPI) e o imposto sobre serviços de qualquer natureza (ISS) - a exação causa a repercussão, isto é, a transferência do ônus da tributação do contribuinte de direito ou legal para o contribuinte de fato, o consumidor. Assim, os impostos diretos estão intrinsecamente relacionados com a capacidade econômica do contribuinte, visto que o sujeito que recolhe o tributo é o mesmo sujeito que suporta o ônus econômico da exação.

Acerca da capacidade econômica, ademais de ser um princípio orientador de obediência obrigatória quando se trata de impostos pessoais, nota-se que o legislador originário adotou, no $\S 1^{\circ}$ do art. 145 da CF/1988, a distinção doutrinária dos impostos diretos em impostos pessoais e impostos reais já mencionada. Tratando-se do imposto de renda, sua natureza pessoal é reconhecida sem grandes discussões (OLIVEIRA, 2008, p. 258). Esclareça-se que, independentemente da pessoalidade do tributo, a relação jurídica tributária sempre se estabelece entre dois sujeitos, "il creditore dell'imposta, titolare della pretesa, ed il debitore dell 'imposta, obbigato alla prestazione” (HENSEL, 1956, p. 73). Todavia, no caso dos tributos reais, a capacidade econômica deve ser aferida em função das características da própria coisa e não de seu proprietário ou possuidor, ainda que o sujeito passivo tributário seja 
sempre a pessoa. Um imóvel de testada maior terá, certamente, maior valor e consequentemente maior base de cálculo para apuração do imposto sobre a propriedade predial e territorial urbana (IPTU).

Em relação aos tributos pessoais, por outro lado, a capacidade econômica deve levar em consideração as características da pessoa, sua situação individual como, no caso das pessoas naturais, o número de filhos dependentes. A pessoalidade é a qualidade daquilo que é pessoa. O conceito de pessoa se formou ao longo de séculos, originando-se inicialmente da exteriorização do argir humano - o personagem no sentido introduzido pelo estoicismo - passando pelo reconhecimento do eu a partir de Descartes e sendo pessoa aquele referido a si mesmo - uma consciência, uma pessoa autorreferente. Por fim, ao dizer Kant que os seres racionais são denominados pessoa porque sua natureza os indica como fins em si mesmos, ou seja, como algo que não pode ser adotado unicamente como meio, e ao afirmar Scheler que a pessoa é o indivíduo com relação à sociedade, a filosofia trouxe um conceito de pessoa dependente de suas relações com os demais, um sujeito de direitos e obrigações membro de um grupo social (ABBAGNANO, 1996, pp. 909-911).

No direito privado, "ser pessoa é fato jurídico" e o nascimento o fato a partir do que a pessoa passa a ter a possibiliddae de ser sujeito de direito. Enfim, para "se ser pessoa não é preciso que seja possível ter quaisqer direitos; basta que possa ter um direito" (MIRANDA, 1970, p. 153). Em que pese o conceito de pessoa haver sido construído pelo direito civil, sabe-se que há autonomia interpretativa no direito tributário, nos termos do art. 107 do CTN. Contudo, o art. 110 do mesmo Código veda a alteração da definição, do conteúdo e do alcance dos institutos, conceitos e formas de direito privado, utilizados pelas constituições e pelas leis 
orgânicas para definir ou limitar competências tributárias. Esta regra da inalterabilidade dos institutos, conceitos e formas do direito privado não precisa ser aplicada ao imposto de renda, uma vez que o inciso III do art. 153 da CF/1988, ao prever a competência da União para institui-lo, não mencionou a incidência sobre a pessoa. Isso leva à conclusão de que a lei complementar ao definir o contribuinte, assim como a lei ordinária federal ao criar o IR, poderia utilizar o conceito de pessoa com significado diferente daquele estabelecido pelo direito privado.

Contudo, isso não ocorreu, pois o contribuinte definido no art. 45 do CTN é o titular da disponibilidade de renda ou de proventos. E, igualmente, o elemento pessoal da regra matriz de incidência (CARVALHO, 2009, p. 336) do IR previsto no art. $1^{\circ}$ da Lei $n^{\circ}$ 7.713/1988 é a pessoa física residente ou domiciliado no Brasil. Esse titular contribuinte é, portanto, um titular de direitos e obrigações, ou seja, uma pessoa. Esse é o significado da pessoalidade do imposto de renda: a conformação da exigência tributária à subjetividade, ou seja, são as características da pessoa que definem o montante a pagar, dotando o tributo de personalização, de subjetividade materialmente falando. Em suma, tratando-se de impostos pessoais, como o IRPF, o atendimento ao princípio da capacidade econômica deve se pautar pelas características da pessoa sobre a qual recai a exigência, conformando o imposto à pessoalidade e dando concretude ao referido princípio. Nesse ponto é preciso afirmar que a capacidade econômica considerada pela renda bruta global auferida pelo contribuinte no período possui um grau mínimo de subjetividade, enquanto essa capacidade, se mensurada por meio da renda líquida possuirá grau máximo de subjetividade, pois necessariamente levará em consideração as características pessoais de cada indivíduo. Pode-se concluir que a base de cálculo para apuração do imposto deve 
ser a renda líquida e não a renda bruta.

A doutrina distingue a capacidade econômica, ou exteriorização da aptidão em potencial para pagar o tributo, da capacidade contributiva, significando a dimensão particular e subjetiva do indivíduo, que o habilita a se submeter efetivamente ao poder de tributar (MARTINS, 1989, pp. 33 e ss.). É essa capacidade contributiva, nas palavras de Francisco Escribano, a "manifestação econômica real, efetiva, certa e atual que ponha em relevo a idônea aptidão para contribuir de determinado sujeito" (1987, p. 199). Viveiros de Castro já afirmava que "assim como não deve haver diferença de situações perante a Lei, assim também a taxação não deve impor os mesmos ônus a pessoas de condições diferentes ou pesar desigualmente sobre pessoas na mesma condição" (1910, p. 154).

A regra matriz de incidência do imposto de renda traz como critério material (CARVALHO, 1981, p. 78) previsto no art. 43 do CTN o verbo "auferir" acompanhado do complemento "renda e proventos de qualquer natureza". Sem adentrar nas intensas e profundas discussões acerca do significado e da abrangência da expressão proventos, o certo é que o fato jurídico que se subsumir a esta hipótese de incidência deve produzir como consequência jurídica o dever de pagar o IR. Neste consequente ou prescritor da regra matriz estão localizados os critérios quantitativo e pessoal, significando o quantum debeatur e os sujeitos da relação jurídica, respectivamente. Enfim, o elo entre os elementos que compõem as diversas hipóteses de incidência do IRPF - renda e proventos - é seu titular (OLIVEIRA, 2008, p. 258). E a apuração do montante de imposto devido por este titular requer a especificação de um sistema de alíquotas e bases de cálculo, porém necessita que esse sistema leve em consideração as características pessoais do contribuinte. Reitere-se que a pessoalidade ou personalização de um tributo não decorre do fato de 
constar do polo passivo da relação jurídica uma pessoa, mesmo porque isso ocorre em relativamente a qualquer tributo, como as taxas, por exemplo. Ao contrário, a pessoalidade de um tributo requer que ele, o tributo, seja materialmente configurado para captar a capacidade de a pessoa individualmente considerada, ser objeto da incidência. Isso porque, sem essa configuração, o imposto deixaria de ser pessoal, ou seja, exigido em face de uma pessoa, dotada de todos os atributos que o ser 'pessoa' recebe do ordenamento jurídico. Como exposto, o significado de pessoa para fins do imposto de renda foi buscado no direito privado, sendo pessoa um fato jurídico decorrente do nascimento. $\mathrm{O}$ ser pessoa e, consequentemente, o poder ser sujeito de direitos (MIRANDA, 1970, p.153), torna o objeto da incidência do IRPF algo especial, pois é preciso que o tributo considere esses direitos. Melhor dizendo, é necessário que o imposto de renda leve em conta os direitos inerentes à pessoa. Quais seriam esses direitos?

Sabe-se que o imposto de renda é dotado de atributos, inclusive de matriz constitucional: pessoalidade referida no $\S 1^{\circ}$ do art. 145 da CF/1988, a generalidade, a progressividade e a universalidade, esses três últimos previstos no inciso I do parágrafo $2^{\circ}$ do art. 153 da Constituição. Há, aditivamente, o atributo da periodicidade, de status infra-constitucional, estipulado no $\S 2^{\circ}$ do art. 144, no art. 104, caput e $9^{\circ}$, II, todos do CTN. Os conceitos de universalidade (XAVIER,2002, pp. 224-226; OLIVEIRA, 2008, p. 54), progressividade (SELIGMAN, 1913, p. 13), periodicidade (OLIVEIRA, 2008, p. 254) e generalidade (QUEIROZ, 2004, p. 38) são de suma importância para a compreensão do imposto de renda. Este último atributo impõe a incidência do imposto sobre todo aquele que se encontre na situação prevista em lei, impedindo a exclusão de determinada categoria de pessoas em função de sua 
ocupação, inclusive quando se tratar de atividades ilícitas. Seu oposto é a seletividade, que permite que determinado tipo de renda seja tributado de modo diferenciado, de forma mais ou menos gravosa. Exemplos de seletividade no IRPF foram os percentuais adicionais de $15 \%, 10 \%$ e 5\% para contribuintes sem filhos ou com filho único, previstos nos arts. 32 a 34 do Decreto-Lei $n^{\circ} 3.200 / 1941$, assim como, atualmente, a fixação da alíquota máxima de $25 \%$ para os ganhos de capital (art. $1^{\circ}$ da Lei $\mathrm{n}^{\mathrm{o}} 13.259 / 2016$ ), enquanto a alíquota incidente sobre o trabalho pode chegar a um patamar maior, igual a 27,5\% (art. $1^{\circ}$ da Lei n ${ }^{\circ} 13.149 / 2015$ ). Pode-se afirmar que as isenções, de forma geral, são manifestações da seletividade, uma vez que a lei isentiva exclui a incidência de determinada renda do alcance o IRPF, a exemplo dos rendimentos provenientes de fundos de investimento imobiliário (art. $3^{\circ}$ da Lei n⿳o 11.033/2004 e art. 125 da Lei no 11.196/2005).

Em suma, a seletividade - seja por meio da fixação de alíquotas diferenciadas, seja através de isenções - no âmbito do IRPF fere o $\S 2^{\circ}$ do inciso I do art. 153 da CF/1988, que reveste de generalidade este imposto. A seletividade dos tributos diretos é considerada indesejável, ademais, por representar 'contranormas' que estabelecem exceções à incidência do tributo, criando 'bolhas fiscais' normalmente obtidas por grupos de interesses econômicos (SANCHES, 2010, p. 41). Como solucionar, então, a necessidade de adequar a exigência do IRPF às condições particulares de cada contribuinte - a exemplo do aposentado portador de moléstia grave? Ou, em outras palavras, como tornar subjetivo e personalizado um tributo, dimensionando-o conforme a capacidade contributiva do indivíduo? Tal tarefa pode ser realizada, entende-se, pela graduação da exigência por meio de deduções aplicadas sobre os rendimentos brutos. Como a base para a incidência do imposto - a base de cálculo - deve ser 
a renda líquida, no caso do aposentado portador de moléstia grave, as despesas com sua saúde e seus cuidados, inclusive com medicamentos e enfermeiros (atualmente não dedutíveis), devem ser deduzidas. $\mathrm{O}$ aperfeiçoamento do sistema de deduções, substituindo as isenções e as regras específicas de tributação conformaria a base de cálculo do imposto - a renda ou o provento auferido - às características do seu titular. Trata-se, nas palavras de Sampaio Dória, da "personalização dos tributos, em função do valor da matéria taxada, dos encargos familiares do contribuinte" (DORIA, 1964, p. 244).

A base de cálculo do IR é tratada no art. 45 do CTN como o montante arbitrado, presumido ou real da renda ou provento auferidos, sobre a qual se fará incidir a alíquota. Há, portanto, uma renda ou um provento auferidos - em seus valores brutos - mas a alíquota incidirá sobre o montante arbitrado, presumido ou real dessa renda ou provento. Para as empresas, esses montantes são denominados de lucro real, lucro presumido e lucro arbitrado (art. $1^{\circ}$ da Lei $n^{\circ}$ 9.430/1996). Tratandose de pessoas físicas, este mesmo montante é a renda líquida obtida pela subtração das deduções sobre os rendimentos brutos (art. $4^{\circ}$ da Lei $n^{\circ}$ 9.250/1995). Por esta razão, enquanto a capacidade econômica do contribuinte no IRPF é mensurada de acordo com a renda bruta, a capacidade contributiva tem por parâmetro a renda líquida, apurada após deduzidos os valores legalmente previstos aplicáveis a cada indivíduo em sua singularidade: contribuições para a previdência, dependentes, despesas médicas e com instrução, entre outras (SILVA, 1974, pp. 20-22). Ou seja, a capacidade contributiva é a dimensão subjetiva e conjuntural da capacidade econômica (MARTINS, 1989, pp. 33 e ss.). Isso explica porque dois indivíduos que possuem a mesma capacidade econômica podem ser dotados de diferentes capacidades contributivas, bastando 
que sobre um deles recaiam despesas com dependentes, por exemplo.

Enfim, a pessoalidade do imposto de renda significa a conformação da incidência do tributo às características pessoais do contribuinte por meio da sua renda líquida. Não se examinará, neste estudo, a figura do responsável tributário, visto não ser este o sujeito que pratica o fato gerador, não havendo possibilidade, portanto, de perquirir sobre sua capacidade. Passa-se a investigar, assim, o grau de pessoalidade de que é e de que deve ser dotado o IRPF, enquanto critério para avaliar o atendimento ao princípio da capacidade contributiva.

\section{CAPACIDADE CONTRIBUTIVA, TRIBUTAÇÃO DA RENDA LÍQUIDA E A SITUAÇÃO PESSOAL DO CONTRIBUINTE}

Se a capacidade econômica do contribuinte depende de sua renda bruta e a capacidade contributiva de sua renda líquida, cabe examinar os critérios necessários e suficientes de diferenciação. Antes, contudo, é preciso enfrentar um aparente conflito: de uma lado, a necessidade de dotar o IRPF de pessoalidade, o que se pretende fazer por meio de deduções para apuração da sua base de cálculo, que é a renda líquida; de outro, a constatação de que toda dedução admitida em lei consiste em renúncia fiscal regulada pelo art. 14 da $\mathrm{LC}^{\circ}$ 101/2000, representando uma redução de arrecadação de imposto que serviria, justamente, à realização de prestações pelo Estado em benefício da totalidade de cidadãos, e não apenas dos contribuintes do IRPF (ROMERO, 2016), cidadãos que atualmente têm renda anual superior a $\mathrm{R} \$ 22.847,76$. Tratase, na verdade, de conflito aparente, seja porque tais situações devem ser solucionadas por meio da ponderação de princípios constitucionais - a capacidade contributiva prevista no $\S 1^{\circ}$ do art. 145 da CF/1988, de um 
lado, e as garantias sociais previstas no art. $6^{\circ}$ da Constituição, de outro - seja porque a seguridade social, abrangendo assistência, previdência e saúde, deve ser financiada por contribuições sociais e não por impostos, como determina o art. 195 da $\mathrm{CF} / 1988$. Há também quem afirme não haver necessidade de adotar como base de cálculo do imposto a renda líquida do contribuinte, pois bastaria aplicar uma alíquota menor sobre a renda bruta para obtenção do mesmo valor a pagar. Trata-se do princípio da renda líquida (MACHADO, 1994, p. 107) que, contudo, não soluciona as diferentes circunstâncias pessoais que envolvem cada contribuinte individualmente considerado. A doutrina (SANCHES, 2010, p. 45) cita dois métodos para configuração da pessoalidade: as deduções da base de cálculo, de um lado, e as deduções sob a forma de abatimentos do imposto, de outro, conforme expostos na tabela (1):

\begin{tabular}{|c|c|}
\hline \multicolumn{2}{|c|}{ Tabela (1) } \\
\hline Primeiro método & Segundo método \\
\hline Renda bruta & Renda bruta \\
\hline - Deduções & IRPF $=$ renda bruta $x$ alíquota \\
\hline$=$ Renda líquida & - Abatimentos do IRPF \\
\hline $\begin{array}{c}\text { IRPF a pagar = renda líquida } x \\
\text { alíquota }\end{array}$ & $=$ IRPF a pagar \\
\hline
\end{tabular}

O segundo método representa na prática uma vinculação de imposto, vedada constitucionalmente por força do art. 167, IV, da $\mathrm{CF} / 1988$. Todavia, é mais favorável para os contribuintes de menor renda, como demonstrado abaixo. Considerou-se, nesta análise, que um cidadão - tabela (2) - tem renda dez vezes maior que o outro - tabela (3) - e que ambos possuem deduções na proporção de $10 \%$ de suas 
respectivas rendas brutas.

\begin{tabular}{|c|c|}
\hline \multicolumn{2}{|c|}{ Tabela (2) } \\
\hline \multicolumn{2}{|c|}{ Imposto a pagar pelo contribuinte de maior renda ${ }^{1}$} \\
\hline Primeiro método & Segundo método \\
\hline Renda bruta $\mathrm{R} \$ 500.000,00$ & Renda bruta $\mathrm{R} \$ 500.000,00$ \\
\hline - Deduções R\$ 50.000,00 & $\begin{array}{c}\mathrm{IRPF}=\mathrm{R} \$ 500.000,00 \mathrm{x} \\
0,275-\mathrm{R} \$ 10.432,32=\mathrm{R} \$ \\
127.067,68\end{array}$ \\
\hline$=$ Renda líquida $\mathrm{R} \$ 450.000,00$ & - Deduções R\$ 50.000,00 \\
\hline $\begin{array}{c}\text { IRPF a pagar }=\mathrm{R} \$ 450.000,00 \\
\mathrm{x} 0,275-\mathrm{R} \$ 10.432,32=\mathrm{R} \$ \\
113.317,68\end{array}$ & $\mathrm{IRPF}$ a pagar $=\mathrm{R} \$ 77.067,68$ \\
\hline \multicolumn{2}{|c|}{$31,98 \%$ de redução de imposto } \\
\hline \multicolumn{2}{|c|}{ Tabela (3) } \\
\hline \multicolumn{2}{|c|}{ Imposto a pagar pelo contribuinte de menor renda ${ }^{2}$} \\
\hline Primeiro método & Segundo método \\
\hline Renda bruta R $\$ 50.000,00$ & Renda bruta R $\$ 50.000,00$ \\
\hline - Deduções R\$ 5.000,00 & $\begin{array}{l}\mathrm{IRPF}=\mathrm{R} \$ 50.000,00 \times 0,225- \\
\mathrm{R} \$ 7.633,51=\mathrm{R} \$ 3.616,49\end{array}$ \\
\hline$=$ Renda líquida $\mathrm{R} \$ 45.000,00$ & - Deduções R\$ 5.000,00 \\
\hline $\begin{array}{c}\text { IRPF a pagar }=R \$ 45.000,00 x \\
0,225-R \$ 7.633,51=R \$ 2.491,49\end{array}$ & IRPF a pagar $=\mathrm{R} \$ 0,00$ \\
\hline \multicolumn{2}{|c|}{$100 \%$ de redução de imposto } \\
\hline
\end{tabular}

O entendimento mais adequado, contudo, parece caminhar no sentido da adoção do primeiro método, vez que a renda líquida é uma imposição constitucional (OLIVEIRA, 2008, p. 430), seja por sua vinculação com a pessoalidade mencionada no $\S 1^{\circ}$ do art. 145 da $\mathrm{CF} / 1988$, seja por força da proibição à vinculação prevista no art. 167. VI, também da Constituição. Enfim, são as deduções da base de 
cálculo que tornam o imposto de renda das pessoas físicas um tributo pessoal (OLIVEIRA, 2008, pp. 434-436). Por essa razão, a pessoalidade é a configuração da incidência do imposto conforme a capacidade individualmente considerada do indivíduo, levando-se em conta, para essa aferição, o conjunto de direitos individuais e sociais que devem ser resguardados. Chega-se neste ponto à dificílima discussão acerca dos direitos fundamentais da pessoa pois, em última instância, determinar quais deduções devem ser admitidas na apuração da base de cálculo do IRPF significa definir o montante suficiente e necessário para garantir ao indivíduo uma apuração da renda líquida que possibilite a manutenção desses direitos, não apenas para si, mas para "as necessidades dos agregados familiares" (SANCHES, 2010, p. 30). Seriam esses direitos (MARQUES, 2014, p. 167) os denominados direitos fundamentais de titularidade individual catalogados no art. $5^{\circ} \mathrm{da} \mathrm{CF} / 1988$ ? Ou os direitos fundamentais coletivos mencionados no art. $6^{\circ}$ da Constituição? Ou ainda outros "para além do conceito formal" (SARLET, 2003, p. 86)? O que deve ser resguardado da renda do contribuinte antes de seu oferecimento à tributação: despesas com sua manutenção e de sua família, gastos com saúde, com educação, com aluguel para moradia, com pagamento de juros na aquisição de casa própria, com transporte, com lazer? Enfim, qual o valor ou percentual admissível como dedutível, necessário e suficiente para dar concretude à pessoalidade no imposto de renda das pessoas físicas? Ou ainda: qual a extensão e quais os limites qualitativos e quantitativos desses direitos?

A personalização de um tributo não é tarefa fácil. Sanches cita o caso da Alemanha ao permitir a "'dedução por todos os contribuintes das despesas que realizam para se deslocar para o seu emprego" (SANCHES, 2010, p. 33), ponderando que o excesso de personalização pode levar à 
percepção de injustas deduções em benefício de determinadas pessoas e que o imposto seria mais justo se fosse menos pessoalizado. À primeira vista pode parecer que a pessoalidade não esteve presente na concepção do IRPF no Brasil, pois a primeira lei - na verdade a lei orçamentária anual $n^{0} 317$, de 21/10/1843 - que previu este imposto o fez sob a forma de uma Contribuição Extraordinária sobre os vencimentos pagos pelos cofres públicos, mediante retenção na fonte pela aplicação de tabela progressiva anual. Na ocasião não se fez referência a qualquer dedução. Àquela época a criação de um imposto direto que pudesse ser graduado conforme a situação de cada pessoa individualmente considerada parecia ser tarefa inalcançável, por exigir cadastros e controles então inexistentes. Porém, mesmo nesse contexto a pessoalidade se tornava necessária, como evidenciou Ruy Barbosa em seu relatório ao Ministério da Fazenda de 1891, ao defender a instituição do imposto de renda em limites suportáveis, salvaguardando a "renda necessária á subsistência individual" (1891, p. 223). De fato, a instituição do IRPF no Brasil pelo art. 31 da Lei $n^{\circ} 4.625 / 1922$ contemplou a pessoalidade, permitindo as seguintes deduções: (i) sob a forma de dedução da renda bruta $\left(1^{\circ}\right.$ método): os impostos e taxas pagos pelo contribuinte; os juros de dívidas; as perdas extraordinárias decorrentes de caso fortuito ou força maior, não seguradas ou indenizadas; as despesas necessárias à percepção da renda; e (ii) sob a forma de abatimento do imposto ( $2^{\circ}$ método): $2 \%$ da renda entre 6:000\$, seis contos de reis - este o valor da renda mínima tributável - e 20:000\$, vinte contos de reis. Este abatimento era limitado também a 50\% do imposto apurado antes do mesmo abatimento.

Em razão da adoção do sistema proposto por Souza Reis, que vigorou de 1924 (art. $3^{\circ}$ Lei n $^{\circ} 4.783 / 1923$ ) a 1964 (arts. $7^{\circ}$ a $9^{\circ}$ da Lei n ${ }^{\circ}$ 4.506/1964), havia diferentes categorias de rendas - indústria e comércio, 
capital inclusive valores mobiliários, trabalho assalariado e trabalho não assalariado - sendo a cada uma delas atribuídas distintas deduções. Os rendimentos líquidos obtidos separadamente eram submetidos às respectivas alíquotas para apuração do imposto. Em seguida calculavase o total de imposto a pagar correspondente à soma dos impostos calculados isoladamente. Em 1926 as categorias passaram a ser chamadas de cédulas, denominação que permaneceu até 31/12/1988 (art. $4^{\circ}$ da Lei $\mathrm{n}^{\mathrm{o}}$ 7.713/1988) quando foi instituído o sistema unitário vigente até hoje. A forma de apuração havia sido alterada, contudo, desde 1964 (art. $7^{\circ}$ da Lei $\mathrm{n}^{\circ}$ 4.506/1964), quando os rendimentos líquidos cedulares passaram a ser somados para, em conjunto, serem sujeitos a uma única alíquota geral, formando o chamado sistema compositório. Em 1950, a classificação cedular dos rendimentos e a criação de deduções próprias para cada um deles - a exemplo das despesas com assinaturas de jornais, revistas e livros técnicos para os rendimentos do trabalho assalariado (Cédula C) e dos gastos com ar-condicionado e consumo de luz para rendimentos de aluguel (Cédula E) - chegavam a ocupar três páginas do formulário da declaração do IRPF (NÓBREGA, 2014, p. 89).

Contudo, é no contexto deste sistema unitário estabelecido desde 1\%01/1989 pela Lei $\mathrm{n}^{\mathrm{o}} 7.713 / 1988$ que se encontra a presente análise, abordando as deduções atualmente admitidas: contribuição para a previdência social, contribuição para a previdência privada, dependentes, despesas médicas, despesas com instrução, despesas de livro caixa e pensão alimentícia judicial paga em razão do direito de família. Esclareça-se que parte das deduções não representam propriamente despesas pessoais do contribuinte com saúde, educação e manutenção de seus dependentes, e sim valores que não correspondem propriamente ao conceito de renda pois suprimidos dos rendimentos percebidos 
pelo cidadão, exemplo da pensão alimentícia e das contribuições à previdência. Ao lado do modelo completo em que são subtraídos da renda bruta os valores das despesas dedutíveis para obtenção da renda líquida - base de cálculo do IRPF - há o modelo simplificado, instituído em 1976 (art. $2^{\circ}, \S 1^{\circ}$, do Decreto-Lei n ${ }^{\circ} 1.424 / 1975$ ). Por esse método, todas as deduções são substituídas por um percentual de $20 \%$ limitado a determinado valor fixado anualmente. Na verdade, ao fixar em $80 \%$ da renda bruta do contribuinte a base de cálculo do IRPF, o modelo simplificado deixa de lado a pessoalidade, por padronizar um montante dedutível independentemente das considerações acerca da situação de um indivíduo em particular.

Feitas essas considerações, retorna-se à questão posta neste estudo: na atual configuração do IRPF a pessoalidade, enquanto conformação do imposto à capacidade contributiva do contribuinte, é atendida? Em outras palavras: o grau de personificação do IRPF é satisfatório ou precário? E como tem evoluído ao longo do tempo: reforçando-se ou tornando--se precário?

\section{DEDUÇÕES DA BASE DE CÁLCULO DO IMPOSTO E PESSOALIDADE: DETERIORAÇÃO E PRECARIEDADE.}

Atualmente os rendimentos anuais líquidos são sujeitos à tabela progressiva contendo alíquotas que variam de 7,5\% a 27,5\% de acordo com faixas crescentes de renda (art. $1^{\circ}$ da Lei $\left.{ }^{\circ} 13.149 / 2015\right)$. A apuração da base de cálculo do IRPF, ou seja, a determinação dos rendimentos líquidos, decorre justamente da adoção de um sistema de deduções, de natureza e valores legalmente especificados - contribuição para a previdência social, contribuição para a previdência privada, dependentes, 
despesas médicas, despesas com instrução, despesas de livro caixa e pensão alimentícia judicial paga em razão do direito de família - que representam ou, deveriam representar, a personificação do imposto. O exame dessa personificação requer, portanto, dupla abordagem: a qualitativa, abrangendo as espécies ou naturezas de gastos que podem e devem ser considerados dedutíveis na apuração da base de cálculo do imposto e a quantitativa, relativa a valores, percentuais e limites de dedutibilidade das despesas na determinação da renda líquida tributável.

Como visto, tal tarefa se estende para além da técnica tributária, vez que cabe ao legislador ordinário definir como e quanto deve haver de pessoalidade no IRPF. O STF já emitiu pronunciamento no sentido de que o Poder Judiciário não pode estabelecer isenções tributárias, redução de impostos ou deduções não previstas em lei, nem ampliar os limites nela estabelecidos, ante a impossibilidade de atuar como legislador positivo, por ocasião do julgamento do REAgR 606179 (Brasil, 2017a), em que foi abordada fixação de limite de valor dos gastos com instrução. Neste mesmo sentido tem decidido o STJ entendendo que cabe à lei, no caso o art. $8^{\circ}$ da Lei n. 9.250/1995, definir a natureza dos gastos dedutíveis a título de instrução - despesas com educação préescolar, de $1^{\circ}, 2^{\circ}$ e $3^{\circ}$ graus, cursos de especialização ou profissionalizantes - não admitindo interpretação extensiva do texto legal para incluir outros serviços ou a aquisição de bens que gerem gastos ao contribuinte não previstos expressamente, como se depreende da leitura do RESP 201401320100 (Brasil, 2017a). Por outro lado, há em tramitação no legislativo federal diversos projetos de lei visando à expansão das deduções ainda não permitidas atualmente, como se observa na tabela (4) abaixo: 


\begin{tabular}{|c|c|}
\hline \multicolumn{2}{|c|}{ Tabela (4) } \\
\hline Dedutibilidade de gastos & Proposição (BRASIL, 2017b) \\
\hline $\begin{array}{c}\text { Enfermeiros; óculos (lentes e } \\
\text { armações); lentes de contato; } \\
\text { medicamentos; vacinas }\end{array}$ & PL 2118/2011; PL 3859/2012; PL \\
$5953 / 2016$ \\
\hline $\begin{array}{c}\text { Nutricionistas; profissionais de } \\
\text { educação física }\end{array}$ & PL 1774/2015 \\
\hline Aparelhos de audição & PL 3479/2008; PL 24/2015 \\
\hline $\begin{array}{c}\text { Aluguéis; juros na aquisição da } \\
\text { casa própria }\end{array}$ & PL 950/2015 \\
\hline $\begin{array}{c}\text { Câmaras de segurança e } \\
\text { alarmes }\end{array}$ & PL 231/2015 \\
\hline Livros didáticos e técnicos & PL 5859/2013 \\
\hline Aulas idiomas & PL 7074/2010; PL 4762/2016 \\
\hline
\end{tabular}

Nessa conjuntura, os dados levantados acerca da pessoalidade no IRPF demonstram a precariedade e a deterioração de sua efetividade visto que, abrangendo o período entre 1\%/01/2001 e 31/12/2014, verifica-se que ter havido redução da personalização do imposto. Pode-se afirmar inicialmente que a análise da pessoalidade, neste período, insere-se em um contexto de expressivo ingresso de cidadãos como pagadores de IRPF. Embora se verifique que o salário mínimo cresceu mais que a renda nacional medida pelo produto interno bruto (PIB) e que a inflação medida pelo índice de preços ao consumidor (IPCA) no mesmo período, elevando em termos reais a renda disponível do indivíduo, o fato de parte desses cidadãos passarem a pagar imposto atuou no sentido da redução da renda disponível. Isto porque, uma vez que a renda tributável mínima cresceu menos que o próprio salário mínimo, e menos ainda que a renda do país (PIB), esse resultado causou a expansão do universo de 
contribuintes, retirando dessa parcela da população parte de sua renda.

Os dados da tabela (5) a seguir evidenciam tal fato, pela comparação entre a renda anual mínima tributável (coluna (2)) e a renda anual com base no salário mínimo (coluna (1)). Vê-se na coluna (3) que em 2001 a renda anual mínima para incidência do IRPF correspondida a 5,21 vezes a renda anual com base no salário mínimo. Esse número sofre redução ano após ano e, em 2014, correspondeu a 2,47 vezes a renda anual com base no salário mínimo. Dessa forma, pessoas que ganhavam renda de até 5,21 salários mínimos não pagariam IRPF em 2001 enquanto em 2014 pessoas que ganhassem 2,47 ou mais salários mínimos já passam a pagar IRPF.

\begin{tabular}{|c|c|c|c|}
\hline \multicolumn{3}{|c|}{ Tabela (5) } \\
\hline Ano & $\begin{array}{c}\text { (1) Renda = Sal. Mín. p/ano } \\
\text { (BRASIL, 2017e) (R\$1,00) }\end{array}$ & $\begin{array}{c}\text { (2) Renda mínima } \\
\text { tributável p/ano } \\
\text { (BRASIL, 2014a) } \\
(\mathrm{R} \$ 1,00)\end{array}$ & $\begin{array}{c}\text { Relação } \\
\text { Renda } \\
\text { mínima } \\
\text { e Salário } \\
\text { mínimo }\end{array}$ \\
\hline 2001 & $2.073,00$ & $10.800,00$ & 5,21 \\
\hline 2002 & $2.340,00$ & $12.696,00$ & 5,43 \\
\hline 2003 & $2.760,00$ & $12.696,00$ & 4,60 \\
\hline 2004 & $3.040,00$ & $12.696,00$ & 4,18 \\
\hline 2005 & $3.440,00$ & $13.968,00$ & 4,06 \\
\hline 2006 & $4.050,00$ & $14.992,32$ & 3,70 \\
\hline 2007 & $4.470,00$ & $15.764,28$ & 3,53 \\
\hline 2008 & $4.980,00$ & $16.473,72$ & 3,31 \\
\hline 2009 & $5.030,00$ & $17.215,08$ & 3,42 \\
\hline 2010 & $6.120,00$ & $17.989,80$ & 2,94 \\
\hline 2011 & $6.530,00$ & $18.799,32$ & 2,88 \\
\hline
\end{tabular}




\begin{tabular}{|l|l|l|l|}
\hline 2012 & $7.464,00$ & $19.645,32$ & 2,63 \\
\hline 2013 & $8.136,00$ & $20.529,36$ & 2,52 \\
\hline 2014 & $8.688,00$ & $21.453,24$ & 2,47 \\
\hline
\end{tabular}

O aumento do número de contribuintes se constata, aditivamente, pela comparação da evolução do número de declarantes - crescimento de $72,7 \%$ entre 2002 e 2014 - com a variação de população economicamente ativa (PEA) que se elevou em apenas 20,96\% neste mesmo no período, como se observa na tabela (6) abaixo:

\begin{tabular}{|c|c|c|}
\hline \multicolumn{3}{|c|}{ Tabela (6) } \\
\hline Ano & $\begin{array}{c}\text { (1) } N^{o} \text { de declarantes } \\
\text { (milhões) (BRASIL, 2014b) }\end{array}$ & $\begin{array}{c}\text { (2) Pop. } \\
\text { Economicamente } \\
\text { Ativa (BEASIL, } \\
\text { 2016) em } \\
\text { dezembro } \\
\text { (milhões) }\end{array}$ \\
\hline 2002 & 15,97 & 20,61 \\
\hline 2003 & 18,05 & 21,62 \\
\hline 2004 & 19,56 & 21,99 \\
\hline 2005 & 22,77 & 22,15 \\
\hline 2006 & 24,04 & 22,66 \\
\hline 2007 & 25,22 & 23,04 \\
\hline 2008 & 25,77 & 23,60 \\
\hline 2009 & 24,38 & 24,00 \\
\hline 2010 & 23,96 & 24,29 \\
\hline 2011 & 24,89 & 24,48 \\
\hline 2012 & 25,87 & 25,22 \\
\hline 2013 & 26,49 & 25,04 \\
\hline 2014 & 27,58 & 24,93 \\
\hline
\end{tabular}




\section{$72,70 \%$}

$20,96 \%$

Pode-se visualizar, aditivamente, a tendência crescente dos valores de imposto de renda pagos pelos contribuintes relativamente ao início do período. Na tabela (7) vê-se que o total dos rendimentos brutos auferidos se elevou em 450,24\% no período, enquanto as deduções pleiteadas pelos contribuintes cresceram em percentual menor, de 307,19\%. Desse modo, o rendimento líquido aumentou mais $(481,38 \%$ na coluna (1)) que os rendimentos brutos $(450,24 \%$ na coluna (3)).

\begin{tabular}{|c|r|r|r|}
\hline \multicolumn{5}{|c|}{ Tabela (7) } \\
\hline Ano & $\begin{array}{c}\text { (1) Total } \\
\text { Rendimentos } \\
\text { Brutos Auferidos } \\
\text { (BRASIL, 2014c) } \\
\text { (R\$ bilhões) }\end{array}$ & $\begin{array}{c}\text { (2) Total } \\
\text { Deduções } \\
\text { Pleiteadas } \\
\text { (BRASIL, } \\
\text { 2014d) (R\$ } \\
\text { bilhões) }\end{array}$ & $\begin{array}{c}\text { (3) Total Rend. } \\
\text { Líquidos } \\
\text { (1)-(2) (R \$ } \\
\text { bilhões) }\end{array}$ \\
\hline 2001 & 436,20 & 78,00 & 358,20 \\
\hline 2002 & 501,40 & 84,97 & 416,43 \\
\hline 2003 & 619,63 & 103,79 & 515,84 \\
\hline 2004 & 736,83 & 120,42 & 616,41 \\
\hline 2005 & 884,66 & 147,19 & 737,47 \\
\hline 2006 & $1.049,06$ & 163,34 & 885,72 \\
\hline 2007 & 985,29 & 171,21 & 814,08 \\
\hline 2008 & $1.263,68$ & 188,32 & $1.075,36$ \\
\hline 2009 & $1.342,89$ & 199,08 & $1.143,81$ \\
\hline 2010 & $1.524,00$ & 214,97 & $1.309,03$ \\
\hline 2011 & $1.773,72$ & 238,26 & $1.535,46$ \\
\hline 2012 & $1.944,56$ & 265,38 & $1.679,18$ \\
\hline
\end{tabular}




\begin{tabular}{|l|r|r|r|}
\hline 2013 & $2.132,74$ & 288,69 & $1.844,05$ \\
\hline 2014 & $2.400,13$ & 317,61 & $2.082,52$ \\
\hline & $450,24 \%$ & $307,19 \%$ & $481,38 \%$ \\
\hline
\end{tabular}

Sob aspecto da evolução das deduções, verifica-se que a renda medida pelo valor do salário mínimo ou pelo montante de rendimentos declarados por contribuintes do IRPF se elevou mais $(319,10 \%$ e $450,24 \%$, nas colunas (1) e (2) \respectivamente) que o valor anual das deduções pleiteadas pelos contribuintes $(307,19 \%$, na coluna $(3))$. Ou seja, as deduções cresceram menos que a renda, como se observa na tabela (8) a seguir.

\begin{tabular}{|c|r|r|r|}
\hline \multicolumn{3}{|c|}{ Tabela (8) } \\
\hline Ano & $\begin{array}{c}\text { (2) Total } \\
\text { p/ano (BRASIL, } \\
\text { 2017e) (R\$,00) } \\
\text { Rendimentos } \\
\text { Brutos Auferidos } \\
\text { (BRASIL, 2014c) } \\
\text { (R\$ bilhões) }\end{array}$ & $\begin{array}{c}\text { (3) Total } \\
\text { Deduções } \\
\text { Pleiteadas } \\
\text { (BRASIL, 2014d) } \\
\text { (R\$ bilhões) }\end{array}$ \\
\hline 2001 & $2.073,00$ & 436,20 & 78,00 \\
\hline 2002 & $2.340,00$ & 501,40 & 84,97 \\
\hline 2003 & $2.760,00$ & 619,63 & 103,79 \\
\hline 2004 & $3.040,00$ & 736,83 & 120,42 \\
\hline 2005 & $3.440,00$ & 884,66 & 147,19 \\
\hline 2006 & $4.050,00$ & $1.049,06$ & 163,34 \\
\hline 2007 & $4.470,00$ & 985,29 & 171,21 \\
\hline 2008 & $4.980,00$ & $1.263,68$ & 188,32 \\
\hline 2009 & $5.030,00$ & $1.342,89$ & 199,08 \\
\hline 2010 & $6.120,00$ & $1.524,00$ & 214,97 \\
\hline 2011 & $6.530,00$ & $1.773,72$ & 238,26 \\
\hline 2012 & $7.464,00$ & $1.944,56$ & 265,38 \\
\hline 2013 & $8.136,00$ & $2.132,74$ & 288,69 \\
\hline 2014 & $8.688,00$ & $2.400,13$ & 317,61 \\
\hline
\end{tabular}


A observação da variação das alíquotas nominais e efetivas do imposto leva à mesma conclusão. Chama-se de alíquota nominal o resultado obtido pela divisão do valor do imposto apurado pelo valor da renda bruta, e de alíquota efetiva o resultado do valor do imposto apurado dividido pelo valor da renda líquida. Pode-se constatar na tabela (10) que a alíquota efetiva do IRPF variou de 9,13\% em 2001 para 14,37\%, crescendo 57,36\% (coluna (7)), enquanto a tabela (9) revela que a alíquota nominal variou de $12,42 \%$ em 2014 para $16,11 \%$, se elevando em apenas 29,73\% (coluna (5)). Isso significa que, após descontadas as deduções, os contribuintes estão pagamento mais imposto em razão de as deduções admitidas e pleiteadas terem crescido menos que a renda tributável.

\begin{tabular}{|c|c|c|c|c|c|}
\hline \multicolumn{6}{|c|}{ Tabela (9) } \\
\hline Ano & $\begin{array}{c}\text { (1) Total } \\
\text { Rendimentos } \\
\text { Brutos } \\
\text { Auferidos } \\
\text { (BRASIL, } \\
\text { 2014c) } \\
\text { R\$ bilhões }\end{array}$ & $\begin{array}{c}(2) \\
\mathrm{N}^{\mathrm{o}} \\
\text { declarantes } \\
\text { milhões } \\
\text { (BRASIL, } \\
\text { 2014b) }\end{array}$ & $\begin{array}{c}(3) \\
\text { Rend. } \\
\text { Bruto por } \\
\text { contribuinte/ } \\
\text { ano } \\
=(1) /(2) \\
(\mathrm{R} \$ 1,00)\end{array}$ & $\begin{array}{c}(4) \\
\text { IRPF } \\
\mathrm{R} \$ 1,00\end{array}$ & $\begin{array}{c}(5) \\
\text { Alíquota } \\
\text { Nominal } \\
=(4) / \\
(3) \\
(\%)\end{array}$ \\
\hline 2001 & 436,20 & 15,23 & $28.640,84$ & $3.556,23^{3}$ & $12,42 \%$ \\
\hline 2002 & 501,40 & 15,97 & $31.396,37$ & & \\
\hline 2003 & 619,63 & 18,05 & $34.328,53$ & & \\
\hline
\end{tabular}




\begin{tabular}{|r|r|r|r|r|l|}
\hline 2004 & 736,83 & 19,56 & $37.670,25$ & & \\
\hline 2005 & 884,66 & 22,77 & $38.852,00$ & & \\
\hline 2006 & $1.049,06$ & 24,04 & $43.638,10$ & & \\
\hline 2007 & 985,29 & 25,22 & $39.067,80$ & & \\
\hline 2008 & $1.263,68$ & 25,77 & $49.036,86$ & & \\
\hline 2009 & $1.342,89$ & 24,38 & $55.081,62$ & & \\
\hline 2010 & $1.524,00$ & 23,96 & $63.606,01$ & & \\
\hline 2011 & $1.773,72$ & 24,89 & $71.262,35$ & & \\
\hline 2012 & $1.944,56$ & 25,87 & $75.166,60$ & & \\
\hline 2013 & $2.132,74$ & 26,49 & $80.511,14$ & & \\
\hline & & & & $14.017,85$ & \\
& & & & $($ BRASIL, & \\
2014 & $2.400,13$ & 27,58 & $87.024,29$ & $2017 \mathrm{~d})^{4}$ & $16,11 \%$ \\
\hline & $450,24 \%$ & $81,09 \%$ & $203,85 \%$ & $294,18 \%$ & $29,73 \%$ \\
\hline
\end{tabular}

\begin{tabular}{|c|c|c|c|c|c|c|c|}
\hline \multicolumn{8}{|c|}{ Tabela (10) } \\
\hline Ano & $\begin{array}{c}\text { (1) Total } \\
\text { Rendi- } \\
\text { mentos } \\
\text { Brutos } \\
\text { Auferidos } \\
\text { (BRASIL, } \\
\text { 2014c) } \\
\text { R\$ bilhões }\end{array}$ & $\begin{array}{c}\text { (2)Total } \\
\text { Deduções } \\
\text { Pleiteadas } \\
\text { R\$ } \\
\text { bilhões } \\
\text { (BRASIL, } \\
\text { 2014d) }\end{array}$ & $\begin{array}{l}\text { (3) Total } \\
\text { Rend. } \\
\text { Líquidos } \\
=(1)- \\
(2) \\
\text { R\$ } \\
\text { bilhões }\end{array}$ & $\begin{array}{c}(4) \mathrm{N}^{\mathrm{o}} \\
\text { declarantes } \\
\text { milhões } \\
\text { (bradil, } \\
\text { 2014b) }\end{array}$ & $\begin{array}{l}\text { (5) Rend. } \\
\text { Líquido } \\
\text { por } \\
\text { contribu- } \\
\text { inte/ } \\
\text { ano }=(3) / \\
(4) \\
\mathrm{R} \$ 1,00\end{array}$ & $\begin{array}{c}(6) \\
\text { IRPF }\end{array}$ & $\begin{array}{c}(7) \\
\text { Alíquota } \\
\text { Efetiva } \\
=(6) / \\
(5) \\
(\%)\end{array}$ \\
\hline 2001 & 436,20 & 78,00 & 358,20 & 15,23 & $23.519,37$ & $2.147,83^{5}$ & $9,13 \%$ \\
\hline 2002 & 501,40 & 84,97 & 416,43 & 15,97 & $26.075,77$ & & \\
\hline 2003 & 619,63 & 103,79 & 515,84 & 18,05 & $28.578,39$ & & \\
\hline 2004 & 736,83 & 120,42 & 616,41 & 19,56 & $31.513,80$ & & \\
\hline 2005 & 884,66 & 147,19 & 737,47 & 22,77 & $32.387,79$ & & \\
\hline 2006 & $1.049,06$ & 163,34 & 885,72 & 24,04 & $36.843,59$ & & \\
\hline 2007 & 985,29 & 171,21 & 814,08 & 25,22 & $32.279,14$ & & \\
\hline
\end{tabular}




\begin{tabular}{|c|c|c|c|c|c|c|c|}
\hline 2008 & $1.263,68$ & 188,32 & $1.075,36$ & 25,77 & $41.729,14$ & & \\
\hline 2009 & $1.342,89$ & 199,08 & $1.143,81$ & 24,38 & $46.915,91$ & & \\
\hline 2010 & $1.524,00$ & 214,97 & $1.309,03$ & 23,96 & $54.633,97$ & & \\
\hline 2011 & $1.773,72$ & 238,26 & $1.535,46$ & 24,89 & $61.689,84$ & & \\
\hline 2012 & $1.944,56$ & 265,38 & $1.679,18$ & 25,87 & $64.908,39$ & & \\
\hline 2013 & $2.132,74$ & 288,69 & $1.844,05$ & 26,49 & $69.613,06$ & & \\
\hline 2014 & $2.400,13$ & 317,61 & $2.082,52$ & 27,58 & $75.508,34$ & $\begin{array}{c}10.850,96 \\
\text { (BRASIL, }^{2} \\
2017 \mathrm{~d})^{6}\end{array}$ & $14,37 \%$ \\
\hline & $450,24 \%$ & $307,19 \%$ & $481,38 \%$ & $81,09 \%$ & $221,05 \%$ & $405,21 \%$ & $57,36 \%$ \\
\hline
\end{tabular}

$\mathrm{O}$ exame das deduções individualmente consideradas conduz aos mesmos resultados. A título ilustrativo, tome-se a dedução com despesas de instrução. Os dados analisados restringem-se ao período de 2007 a 2014 em razão da criação do Fundo de Manutenção e Desenvolvimento da Educação Básica e de Valorização dos Profissionais da Educação (Fundeb) pela Emenda Constitucional n ${ }^{\circ} 53 / 2006$, regulado pela Lei $n^{\circ}$ 11.494/2007. Considerando-se que os gastos governamentais associados às políticas públicas podem servir como indicador da evolução de valores destinados aos serviços de educação, constata-se na tabela (11) que o valor mínimo por aluno estabelecido pelo Ministério da Educação se elevou na proporção de 141,29\% entre 2007 e 2014 (coluna (1)).

\begin{tabular}{|c|c|c|c|}
\hline \multicolumn{4}{|c|}{ Tabela (11) } \\
\hline Ano & $\begin{array}{c}\text { (1) Valor Mínimo } \\
\text { por Aluno } \\
\text { (BRASIL, 2017c) }\end{array}$ & $\begin{array}{c}\text { (2) Valor Limite } \\
\text { Dedução Despesas } \\
\text { com Instrução } \\
\text { (BRASIL, 2014d) }\end{array}$ & $\begin{array}{c}\text { (3) Variação } \\
\text { anual do IPCA } \\
\text { (BRASIL, } \\
2015)(\%)\end{array}$ \\
\hline 2007 & 947,24 & $2.480,66$ & 4,46 \\
\hline 2008 & $1.132,34$ & $2.592,29$ & 5,90 \\
\hline 2009 & $1.350,09$ & $2.708,94$ & 4,31 \\
\hline 2010 & $1.415,97$ & $2.830,84$ & 5,91 \\
\hline
\end{tabular}




\begin{tabular}{|c|c|c|c|}
\hline 2011 & $1.722,05$ & $2.958,23$ & 6,50 \\
\hline 2012 & $2.096,68$ & $3.091,35$ & 5,84 \\
\hline 2013 & $2.022,51$ & $3.230,46$ & 5,91 \\
\hline 2014 & $2.285,57$ & $3.375,83$ & 6,41 \\
\hline & $141,29 \%$ & $36,09 \%$ & $45,24 \%$ \\
\hline
\end{tabular}

Esta mesma tabela (11) apresenta os limites individuais anuais para dedução de gastos com a educação do contribuinte ou de seus dependentes. Vê-se que, entre os anos de 2007 e 2014 o valor mínimo se elevou em apenas $36,09 \%$ (coluna (2)), indicando um crescimento bastante inferior ao praticado pelo próprio Estado em sua política de gastos com educação: $141,29 \%$ versus $36,09 \%$. Na verdade, o acréscimo do valor limite desta dedução ficou inclusive abaixo da variação do IPCA, que no período se elevou em 45,24\%, conforme coluna (3) da tabela (11). Esses dados auxiliam a compreender o porquê de as deduções legais terem perdido espaço na mensuração do quantum debeatur dos contribuintes do IRPF, até porque indicam a relação direta entre deduções legais e pessoalidade do imposto de renda das pessoas físicas.

Enfim, essas pontuais demonstrações vêm demonstrar que o IRPF, apesar de consagrado pela doutrinária e jurisprudência como tributo ontologicamente relacionado ao princípio da capacidade econômica, não se encontra satisfatoriamente dotado de pessoalidade - seja por não abranger diversos gastos que afetam a capacidade contributiva (capacidade econômica concreta e individualizada) a exemplo de gastos de aluguel com moradia, seja por ter sido demonstrada sua evolução negativa ao longo do período analisado (redução do montante de deduções). 


\section{CONCLUSÃO}

O exercício do poder de tributar do Estado é sujeito a uma diversidade de limitações. Entre elas, o princípio da capacidade econômica determina a conformação da exigência tributária aos haveres do contribuinte. No caso específico de um imposto pessoal - o IRPF - a Constituição foi além, indicando os atributos a ele inerentes: a generalidade, a universalidade e a progressividade. A natureza pessoal não consiste em mera classificação doutrinária do imposto. Ao contrário, ela exige a conformação do tributo à subjetividade, isto é, as características da pessoa devem definir o montante a pagar. Tal personifiação, ou pessoalização, ou subjetivação da exigência tributária requer a medição de uma outra capacidade além da econômica. Esta se apresenta por meio da exteriorização da riqueza - a percepção de renda bruta - enquando a capacidade contributiva consiste na dimensão particular e subjetiva que habilita o indivíduo a contribuir. Não se deve confundir a pessoalidade com a seletividade, esta demonstrada por meio de excepcionais isenções e da fixação de alíquotas diferenciadas aplicáveis a certos tipos de rendimentos. A adequação do IRPF às condições particulares de cada contribuinte deve ser realizada por meio de deduções da renda bruta - a exemplo de despesas com instrução - para que somente a renda líquida (indicadora da capacidade contributiva) se sujeite ao imposto.

Os critérios qualitativos - quais gastos devem ser dedutíveis - e quantitativos - qual valor ou percentual da despesa será dedutível devem ser examinados com atenção uma vez que, de um lado, precisam levar em consideração o montante suficiente e necessário para garantir ao indivíduo a apuração da renda líquida que possibilite a manutenção de seus direitos fundamentais, individuais e coletivos. Por outro lado, 
as deduções representam uma renúncia de receitas pelo Estado, o que significa a redução de recursos que poderiam ser utilizados na concretização de serviços públicos. Enfim, como determinar o que deve e pode ser objeto de dedução: despesas com manutenção do contribuinte e de sua família, gastos com saúde, com educação, com aluguel para moradia, com pagamento de juros na aquisição de casa própria, com transporte, com lazer? Qual o valor ou percentual admissível como dedutível dessas despesas?

A pessoalidade do IRPF esteve presente desde sua instituição, vez que o art. 31 da Lei n ${ }^{\circ}$ 4.625/1922 previa a dedução de gastos com impostos e taxas pagos pelo contribuinte, com juros de dívidas, com perdas extraordinárias decorrentes de caso fortuito ou força maior, e com despesas necessárias à percepção da renda. Parte desses gastos não são dedutíveis atualmente, sendo admitidas para apuração da base de cálculo do IRPF, por força do art. $8^{\circ}$ da Lei $n^{\circ}$ 9.250/1996, somente as seguintes despesas: a contribuição para a previdência social, contribuição para a previdência privada, dependentes, despesas médicas, despesas com instrução, despesas de livro caixa e pensão alimentícia judicial paga em razão do direito de família. Contudo, os dados levantados acerca da pessoalidade no IRPF demonstram a precariedade de sua efetividade visto que, abrangendo o período entre 1\%01/2001 e 31/12/2014, verifica-se a proposição de diversos projetos de lei pleiteando a ampliação do rol de gastos dedutíveis. Verifica-se, ademais, ter havido deterioração da personalização do imposto no período sob análise. Tal afirmação decorre das seguintes constatações: (i) a existência de inúmeras demonstrações de seletividade do IRPF inseridas por meio de isenções e da fixação de alíquotas diferenciadas para rendimentos de diversas naturezas, a exemplo dos lucros e dividendos e dos rendimentos de aplicações financeiras; (ii) 
a imposição de restrições qualitativas e de limitações quantitativas às deduções da base de cálculo do imposto. Tomando-se como exemplo a dedução com despesas de instrução, constata-se que o valor mínimo por aluno estabelecido pelo Ministério da Educação elevou-se na proporção de $141,29 \%$ entre 2007 e 2014 , enquanto os limites individuais anuais para dedução de gastos com a educação do contribuinte ou de seus dependentes somente cresceu, no mesmo período, 36,09\%, percentual menor inclusive que a variação do IPCA, que no período se elevou em 45,24\%; (iii) o crescente ingresso de cidadãos no universo de pagadores de IRPF. Essa expansão do universo de contribuintes se demonstrou mediante a comparação entre a variação dos montantes arrecadados versus a variação da inflação, do salário mínimo e da renda do país, bem como pelo acréscimo do número de declarantes superior ao da população economicamente ativa; (iv) a elevação do total dos rendimentos brutos auferidos em 450,24\% no período, bastante superior ao aumento do total das deduções pleiteadas pelos contribuintes que cresceram em percentual menor, de 307,19\%. Dessa forma, o rendimento líquido se elevou (481,38\%), bem mais que os rendimentos brutos (450,24\%); (v) o montante de rendimentos brutos declarados por contribuintes do IRPF se elevou mais $(450,24 \%)$ que o valor anual das deduções pleiteadas pelos contribuintes $(307,19 \%)$. Ou seja, as deduções cresceram menos que a renda; (vi) a alíquota efetiva do IRPF - mensurada em função da renda líquida - variou de 9,13\% em 2001 para 14,37\%, crescendo 57,36\%, enquanto a alíquota nominal - medida em função da renda bruta - variou de $12,42 \%$ em 2014 para 16,11\%, se elevando em apenas $29,73 \%$.

O conjunto desses fatores permite concluir que havia em 2014, em relação a 2001, mais contribuintes pagando IRPF, e em valor maior relativamente às suas respectivas rendas e considerações pessoais. Enfim, 
essas considerações levam a crer que o IRPF, apesar de consagrado pela doutrinária e jurisprudência como tributo ontologicamente relacionado aos princípios da capacidade econômica e da capacidade contributiva, possui precário grau de pessoalidade que, inclusive, vem se deteriorando ao longo desses últimos anos.

\section{REFERÊNCIAS}

ABBAGNANO, Nicola. Diccionario de Filosofia. Mexico: Fondo de Cultura Económica, 1996.

BALEEIRO, Aliomar. Uma Introdução à Ciência das Finanças. Rio de Janeiro: Forense, 2006.

BARBOSA, Ruy. Relatório de 15/01/1891. Disponível em:< http:// www2.senado.leg.br/bdsf/item/id/222318 > . Acesso em: 20/01/2017.

BERLIRI, Antonio. Principi Generali del Diritto Tributario.

Bologna: Prof. Riccardo Pàtron, 1962.

BRASIL. Ministério da Fazenda. Secretaria da Receita Federal. Limite de isenção do Imposto de Renda das Pessoas Físicas. 2014a. Disponível em: <http://idg.receita.fazenda.gov.br/dados/receitadata/estudos-e-tributarios-e-aduaneiros/estudos-e-estatisticas/11-08-2014-grandes-numeros-dirpf $>$. Acesso em:16/01/2017.

. Ministério da Fazenda. Secretaria da Receita Federal. Número de declarantes do IRPF. 2014b. Disponível em: $<$ http:// idg.receita.fazenda.gov.br/dados/receitadata/estudos-e-tributarios-e-aduaneiros/estudos-e-estatisticas/11-08-2014-grandes-numeros-dirpf $>$. Acesso em 16/01/2017.

. Ministério da Fazenda. Secretaria da Receita Federal. 
Rendimento bruto declarado. 2014c. Disponível em: $<$ http://idg.receita.fazenda.gov.br/dados/receitadata/estudos-e-tributarios-e-aduaneiros/estudos-e-estatisticas/11-08-2014-grandes-numeros-dirpf $>$. Acesso em 16/01/2017.

. Ministério da Fazenda. Secretaria da Receita Federal.

Total deduções pleiteadas. 2014d. Disponível em: < http://idg.receita. fazenda.gov.br/dados/receitadata/estudos-e-tributarios-e-aduaneiros/ estudos-e-estatisticas/11-08-2014-grandes-numeros-dirpf $>$. Acesso em $16 / 01 / 2017$.

. Instituto Brasileiro de Geografia e Estatística. Sistema Nacional de Índices de Preços ao Consumidor. 2015. Disponível em: <http://www.ibge.gov.br/home/estatistica/indicadores /precos/ inpc_ipca/defaultseriesHist.shtm>. Acesso em: 20/01/2017.

. Instituto Brasileiro de Geografia e Estatística. População Economicamente Ativa (PEA). 2016. http://www.ibge.gov.br/ home/estatistica/indicadores/trabalhoerendimento/pme_nova/ defaulttab hist.shtm. Acesso em: 20/01/2017.

. Jurisprudência. 2017a. Disponível em: < http://www. cjf.jus.br/juris/unificada/Resposta>. 2017. Acesso em: 20/01/2017.

. Legislação. Projetos de Lei. 2017b. Disponível em: < http://www.camara.leg.br/buscaProposicoesWeb/pesquisaAvancada>. Acesso em: 16/01/2017.

. Ministério da Fazenda. Portarias Interministeriais Ministério da Fazenda/Ministério da Educação. 2017c. № 1.030, de 06/11/2007; no 1.027, de 19/08/2008; n ${ }^{\circ} 221$, de10/03/2009; $\mathrm{n}^{\mathrm{o}} 1.227 / 2009 ; \mathrm{n}^{\mathrm{o}} 1.459 / 2010 ; \mathrm{n}^{\mathrm{o}} 1.809 / 2011 ; \mathrm{n}^{\mathrm{o}} 1.496 / 2012 ; \mathrm{e}^{\mathrm{o}}$ 1.927/2013. Disponível em: <http://fazenda.gov.br/acesso-a-informacao/institucional/legislacao/portarias-interministeriais/>. Acesso em: 14/01/2017. 
. Tabelas do IRPF. 2017d. Disponível em: <http://idg. receita.fazenda.gov.br/acesso-rapido/tributos/irpf-imposto-de-renda-pessoa-fisica\#c-lculo-anual-do-irpf $>$. Acesso em: 17/01/2017.

. Salário Mínimo 2017. Salário mínimo anual $=12 \mathrm{x}$ salário mínimo mensal. 2017e. Disponível em: $<$ http://salariominimo2016.blog.br/>. Acesso em: 23/01/2017.

CARVALHO, Paulo de Barros. Teoria da Norma Tributária. São Paulo: Revista dos Tribunais, 1981.

. Curso de Direito Tributário. São Paulo: Saraiva, 2009.

CASTRO, Augusto Olympio Viveiros de. Tratado dos Impostos. Rio de Janeiro: Imprensa Nacional, 1910.

DÓRIA, Antônio Roberto Sampaio. Princípios constitucionais tributários e a cláusula due process of law. São Paulo: Revista dos Tribunais, 1964.

ESCRIBANO, Francisco. La Configuración Juridica del Deber de Contribuir. Perfiles Constitucionales. Córdoba: Civitas, 1987.

HENSEL, Albert. Diritto Tributario. Milano: Dott A. Giuffrè,1956.

JARACH, Dino. Curso superior de derecho tributário, Tomo 1.

Buenos Aires: Liceo Profissional Lima, s/d.

JÈZE, Gaston. Cours de finances publiques. Paris: Marcel Giard, 1931. Up ud. PEREIRA, Manuel Henrique de Freitas. Fiscalidade.

Coimbra: Almedina, 2009.

MACHADO, Brandão. Breve exame crítico do art. 43 do CTN. In: MARTINS, Ives Gandra da Silva (Coord.). Estudos sobre o imposto 
de renda (Em memória de Henry Tilbery). São Paulo: Resenha Tributária, 1994.

MARQUES, Clarissa. O conceito de direitos fundamentais. In:

BRANDÃO, Cláudio (Coord.) Direitos humanos e fundamentais em perspectiva. São Paulo: Atlas, 2014.

MARTINS, Ives Gandra. Impostos: comentários ao CTN. Volume 5. São Paulo: Revista dos Tribunais, 1979.

\section{. Capacidade Econômica e Capacidade Contributiva.}

Caderno de Pesquisas Tributárias, nº 14. São Paulo, Resenha Tributária, 1989.

MIRANDA, Pontes de. Tratado de Direito Privado. Tomo I. Rio de Janeiro: Borsoi, 1970.

NABAIS, José Casalta. O dever fundamental de pagar impostos. Contributo para a compreensão constitucional do Estado fiscal contemporâneo. Coimbra: Almedina, 1998.

NÓBREGA, Cristóvão Barcelos da. História do Imposto de Renda no Brasil, um enfoque da pessoa física (1922-2013). Brasília: Receita Federal: 2014.

OLIVEIRA, Ricardo Mariz de. Fundamentos do Imposto de Renda. São Paulo: Quartier Latin, 2008.

QUEIROZ, Mary Elbe. Imposto sobre a Renda e Proventos de Qualquer Natureza. Barueri: Manole, 2004.

ROMERO, Cristiano. Deduções do IR: um debate necessário. In: Valor Econômico. 21/12/2016. Disponível em: <http://www.valor.com. br/brasil/4814323/deducoes-do-ir-um-debate-necessario $>$. Acesso em: 
22/12/2016.

SAMUELSON, Paul. Introdução à Análise Econômica. Volume I. Rio de Janeiro: Agir, 1979.

SANCHES, J. L. Saldanha. Justiça Fiscal. Lisboa: Relógio D’Água, 2010.

SARLET, Ingo. A eficácia dos direitos fundamentais. Porto Alegre: Livraria do Advogado, 2003.

SCHOUERI, Luís Eduardo. Normas Tributárias Indutoras e Intervenção Econômica. Rio de Janeiro: Forense, 2005.

SELIGMAN, Edwin R. A . L'impôt sur le revenue. Paris: M. Giard \& E. Brière, 1913.

SILVA, Fernando A. Rezende da. O Imposto sobre a renda e a justiça fiscal. Rio de Janeiro: IPEA/INPES, 1974.

SLEMROD, Joel; BAKIJA, Jon. Taxing Ourselves. Cambridge, Massachusetts: Mit Press, 2004.

SOUSA, Rubens Gomes de. Compêndio de Legislação Tributária. Rio de Janeiro: Edições Financeiras S/A, s/d.

. Ainda a distinção entre taxa e imposto. Revista de Direito Público, nº 21, 1972.

TIPKE, Klaus. Moral Tributaria del Estado y de los Contribuyentes. Madrid: Marcial Pons, 2002.

XAVIER, Alberto. Manual de Direito Fiscal., Volume 1. Lisboa: Almedina, 1981. 


\section{. Direito tributário internacional do Brasil: tributação}

das operações internacionais. $5^{\mathrm{a}}$ ed. Rio de Janeiro: Forense, 2002.

Como citar: COELHO, André Felipe Canuto; BORBA, Bruna Estima. Imposto de renda da pessoa física e pessoalidade: uma relação precária e em deterioração. Revista do Direito Público. Londrina, v. 13, n. 1, p. 188-225, abr. 2018. DOI: 10.5433/1980-511X2018v13n1p188. ISSN: 1980-511X.

Recebido em: 29/01/2017

Aprovado em: 28/03/2018 